\section{Implantação das ações intersetoriais de mobilização social para o controle da dengue na Bahia, Brasil}

\author{
Inter-sector social mobilization for dengue control \\ in Bahia State, Brazil
}

\author{
1 Universidade Estadual de \\ Feira de Santana, Feira de \\ Santana,Brasil. \\ 2 Instituto de Saúde Coletiva, \\ Universidade Federal da \\ Bahia, Salvador, Brasil. \\ Correspondência \\ E. C. Lima \\ Universidade Estadual de \\ Feira de Santana. \\ Rua Odilon Correia 369, \\ Vitoria da Conquista, $B A$ \\ 45005-028, Brasil. \\ elviracaires@hotmail.com
}

\section{Abstract}

Discussions on the health-disease process and health promotion indicate the need to reach beyond the limits of the health sector itself to link knowledge from various fields in order to promote better health conditions for the population. Inter-sector approaches have thus emerged as a new rationale for guiding public policies. This study aimed to analyze the implementation of inter-sector actions in social mobilization for dengue control in Bahia State, Brazil, from 2008 to 2009, using evaluative research. A log frame was developed to define criteria for assessing the degree of implementation of the above-mentioned actions (implemented; partially implemented; not implemented). The results identified political support from government agencies as the main positive factor for inter-sector practices. Barriers included the concentration of responsibilities in a single sector and lack of planning as a work tool. The results emphasize inter-sector linkage as a persistent challenge.

Intersectorial Action; Dengue; Social Participation; Public Policies; Evaluation
Elvira Caires de Lima 1

Ana Luiza Queiroz Vilasbôas 2

\section{Introdução}

A saúde é um direito de todos e dever do Estado. Medidas que visam à redução dos riscos de doenças e demais agravos, além de ações de promoção, proteção e recuperação da saúde 1, são formas de se garantir esse direito. $\mathrm{O}$ enfoque de controle de riscos e agravos amplia o conceito de saúde, de modo que o "estado saudável” não mais está associado apenas à ausência de doenças. Condicionantes e determinantes do processo saúde-doença ganham destaque, a exemplo do saneamento básico, meio ambiente, educação, lazer, transporte, moradia, renda, alimentação e do acesso aos bens e serviços essenciais 2 .

O conceito ampliado de saúde indica a necessidade de ações que extrapolem os limites do setor e que estabeleçam diálogo com outros setores 3 , a fim de operacionalizar parcerias e articular saberes e experiências para a solução dos problemas encontrados. Essa forma de enfrentamento dos problemas de saúde tem sido denominada intersetorialidade 4 .

Considera-se que a intersetorialidade pode se tornar um dos eixos principais para a consolidação de um sistema de saúde mais efetivo. Tal perspectiva implica mudanças na gestão, ainda muito setorializada, das políticas públicas associadas à qualidade de vida, contribuindo, dessa forma, para melhorar os indicadores de saúde da população. 
A intersetorialidade, na qualidade de ferramenta de políticas públicas saudáveis e de promoção da saúde, extrapola os limites do aparelho estatal e exige maior articulação deste com a população ${ }^{5}$. A participação popular é primordial para aumentar o poder das comunidades e sua consciência política 6 . No entanto, há uma certa complexidade em se constituir a relação intersetorial. É necessário estabelecer distribuição de poder mais igualitária entre os setores, tornando suas relações mais horizontalizadas. Desse modo, pretende-se evitar a subordinação de um setor a outro e a conformação de dificuldades e resistências por parte de alguns deles, o que dificulta a operacionalização de práticas intersetoriais 7,8 .

Apesar da coerência existente entre a proposta da intersetorialidade e a concepção ampliada do processo saúde-doença, há pouco conhecimento acumulado sobre experiências relacionadas às práticas intersetoriais. A insuficiência de estudos empíricos sobre ações intersetoriais vinculadas a problemas de saúde foi o estímulo à realização desse estudo.

Diante disso, em virtude da grande relevância epidemiológica da dengue e da necessidade de, para controlá-la, extrapolar os limites do setor saúde, escolheu-se como lócus deste estudo o Comitê Estadual de Mobilização Social de Prevenção e Controle da Dengue na Bahia (Comitê). A escolha do Comitê deveu-se também à sua constituição e regimento interno, que indicavam proposta de trabalho intersetorial. Constituído por diversos segmentos da sociedade, num total de 36 instituições, o Comitê destacava, entre suas responsabilidades, a promoção de ações de educação em saúde, comunicação e mobilização social, que deveriam ser organizadas de forma articulada entre os diversos setores 9 .

A estruturação de comitês de mobilização social é parte integrante de um dos componentes do Programa Nacional de Controle da Dengue (PNCD), elaborado pelo Ministério da Saúde em parceria com estados e municípios, que corresponde às ações integradas de educação em saúde, comunicação e mobilização social ${ }^{10}$. Tem como objetivo promover a adesão da sociedade civil organizada mediante ações que contribuam para o controle da dengue.

Este estudo propôs analisar o processo de implantação das ações intersetoriais do Comitê Estadual de Mobilização Social de Prevenção e Controle da Dengue na Bahia, no período de 2008 a 2009.

\section{Intersetorialidade em saúde}

A intersetorialidade é definida como articulação entre saberes e experiências para solução dos problemas encontrados 4 ; como busca da complementaridade, reciprocidade e vínculo na ação 3 ; como uma nova maneira de planejar, executar e controlar a prestação de serviços, a fim de garantir acesso igual aos desiguais 11, e como a união de esforços para se conseguir melhores resultados do que se obteria trabalhando de forma isolada 12. Para fins do presente estudo, considera-se intersetorialidade como articulação de diversos setores, com o propósito de somar forças, potencialidades e recursos para a solução de um problema comum, no caso a dengue.

São necessárias estratégias que possibilitem a operacionalização das ações intersetoriais, empregando-se de meios e instrumentos que possam minimizar os obstáculos encontrados e potencializar as variáveis favoráveis. Nesse sentido, a comunicação e a educação apresentam-se como eixos essenciais desse processo. Em um espaço compartilhado por distintos setores, representado por sujeitos de identidades diferentes, para que a comunicação seja efetiva e atinja seu objetivo, faz-se necessário inovar suas práticas e enfocar suas múltiplas dimensões. A comunicação não poderá ser vista apenas como a transmissão de uma mensagem (emissor-receptor) e não poderá ocorrer de forma autoritária, conduzida por um único setor; há necessidade de se construir um processo democrático e descentralizado, de modo a estabelecer, de forma coletiva, soluções para os problemas encontrados. A comunicação passa a ser compreendida como a circulação e interação de significados 13 .

Outro elemento importante nesse processo é a utilização do planejamento como ferramenta de articulação e de integração das decisões 11. Utilizou-se como elemento norteador deste estudo o Planejamento Estratégico Situacional (PES), elaborado por Matus 14, não só por algumas de suas características que se adéquam à proposta de trabalho intersetorial, mas também por ser um método que se propõe a trabalhar problemas complexos abordando suas múltiplas dimensões.

No PES, destaca-se a relevância dada ao sujeito que planeja não como um elemento externo da realidade planejada, mas como integrante dessa realidade; o sujeito não é distinto do objeto planejado e o objeto planejado compreende outros sujeitos que também planejam. O planejamento pode ser utilizado para tentar construir uma identidade dos grupos a partir das identidades e subjetividade dos sujeitos, sem, contudo, cercear as identidades individuais 15; a 
corresponsabilidade estimula a motivação para a construção compartilhada ${ }^{3}$. Essa perspectiva se ajusta à proposta da intersetorialidade, pois a construção de uma identidade coletiva, sem anular a subjetividade dos componentes do grupo, contribuiria para que os sujeitos se identificassem e se comprometessem com os objetivos do grupo, desenvolvendo a possibilidade de uma ação teleológica.

A intersetorialidade envolve a participação de vários segmentos e setores, constituídos por sujeitos distintos; estes passam a representar dentro de determinados espaços - comitês, conselhos, colegiados, grupos - os interesses e missões que suas organizações defendem. Além disso, os sujeitos estão imbuídos de suas individualidades e subjetividades, que não podem ser ignoradas, pois influenciam nas decisões e postura de cada ator em face de determinados grupos e, também, nas relações estabelecidas entre os sujeitos. Sendo assim, é necessária a criação de espaços onde as relações de poder sejam reconstruídas, elaborando um poder compartilhado e articulando interesses entre as diversas organizações envolvidas com a proposta da intersetorialidade 8,16 .

O triângulo de governo proposto por Matus 14 é constituído da articulação de três variáveis que interferem diretamente no processo de condução de um determinado governo. São elas: o projeto de governo, a capacidade de governo e a governabilidade do sistema. Essas variáveis são interdependentes, e o desempenho e o resultado de uma interferem na outra variável.

Analisando os espaços de construção da intersetorialidade, espera-se que cada ator, representante de um setor específico, possua governabilidade suficiente para interferir nas políticas, decisões e ações desse setor, contribuindo para o alcance de determinada proposta intersetorial. Dessa forma, a governabilidade do sistema está relacionada com a possibilidade de ação desse ator e sua capacidade de controlar os efeitos dessa ação. A governabilidade de determinado ator é influenciada por seu capital político, que seria sua influência política sobre a situação na qual está inserido, e por seu poder político 17 .

A governabilidade do sistema também é influenciada pela capacidade de governo do ator, que corresponde à capacidade de definir meios eficazes de governar. Resultados mais eficazes dependerão do projeto de governo estabelecido, que é o projeto de ação proposto para alcançar determinado objetivo. Destaca-se que o projeto de governo não é produto apenas do interesse do ator que governa, mas da sua capacidade de governo.

Portanto, a efetividade de ações intersetoriais envolve a governabilidade do ator no seu setor $\mathrm{e}$ nos espaços de construção da intersetorialidade; a construção de um projeto de governo adequado à realidade na qual se quer intervir, com viabilidade; e a capacidade de governo dos atores envolvidos na proposta de articulação intersetorial.

\section{Metodologia}

Realizou-se pesquisa avaliativa sob a forma de estudo de caso único, de caráter exploratório. Optou-se por realizar parte do componente 1 da Análise de Implantação, que corresponde à estimativa do grau de implantação da intervenção 18. O Comitê Estadual de Mobilização Social de Prevenção e Controle da Dengue no Estado Bahia foi criado em 2008 por decreto estadual para atender às especificações do PNCD 10.

Para analisar o processo de implantação das ações intersetoriais de mobilização social para o combate à dengue, procurou-se, em primeiro lugar, caracterizar tais ações mediante a descrição das atividades realizadas pelo Comitê e a identificação dos sujeitos envolvidos quanto à sua capacidade de governo. Em seguida, buscouse estimar o grau de implantação das ações intersetoriais consideradas, por meio da aplicação de critérios derivados do modelo teórico-lógico elaborado pelas autoras. Por fim, os fatores facilitadores e restritivos para implantação das ações intersetoriais sob foco de análise foram descritos, tendo como base a caracterização das relações sociais entre os sujeitos envolvidos com o Comitê e a governabilidade de tais sujeitos quanto à realização das ações intersetoriais acordadas no espaço do Comitê.

Portanto, a coleta, o processamento e a análise dos dados empíricos dessa investigação foram sustentados por um plano de análise (Tabela 1), que tratou de indicar a concepção adotada sobre ações intersetoriais. Essas ações se realizam mediante planejamento, monitoramento e avaliação compartilhados entre as distintas instituições envolvidas na solução de um determinado problema, cuja viabilidade decorre da capacidade de governo e da governabilidade dos sujeitos que as representam. Ademais, as relações sociais existentes entre tais sujeitos, sejam de cooperação, sejam de conflito, modulam a realização das ações intersetoriais.

Valendo-se do plano de análise, construiu-se uma matriz para a elaboração dos instrumentos utilizadas na coleta dos dados, a fim de estabelecer a relação existente entre os objetivos do estudo e os achados empíricos. Foram utilizadas fontes de dados primários e secundários, por meio da realização de 13 entrevistas semiestruturadas 
Tabela 1

Plano de análise das ações intersetoriais de mobilização social para o controle da dengue na Bahia, Brasil.

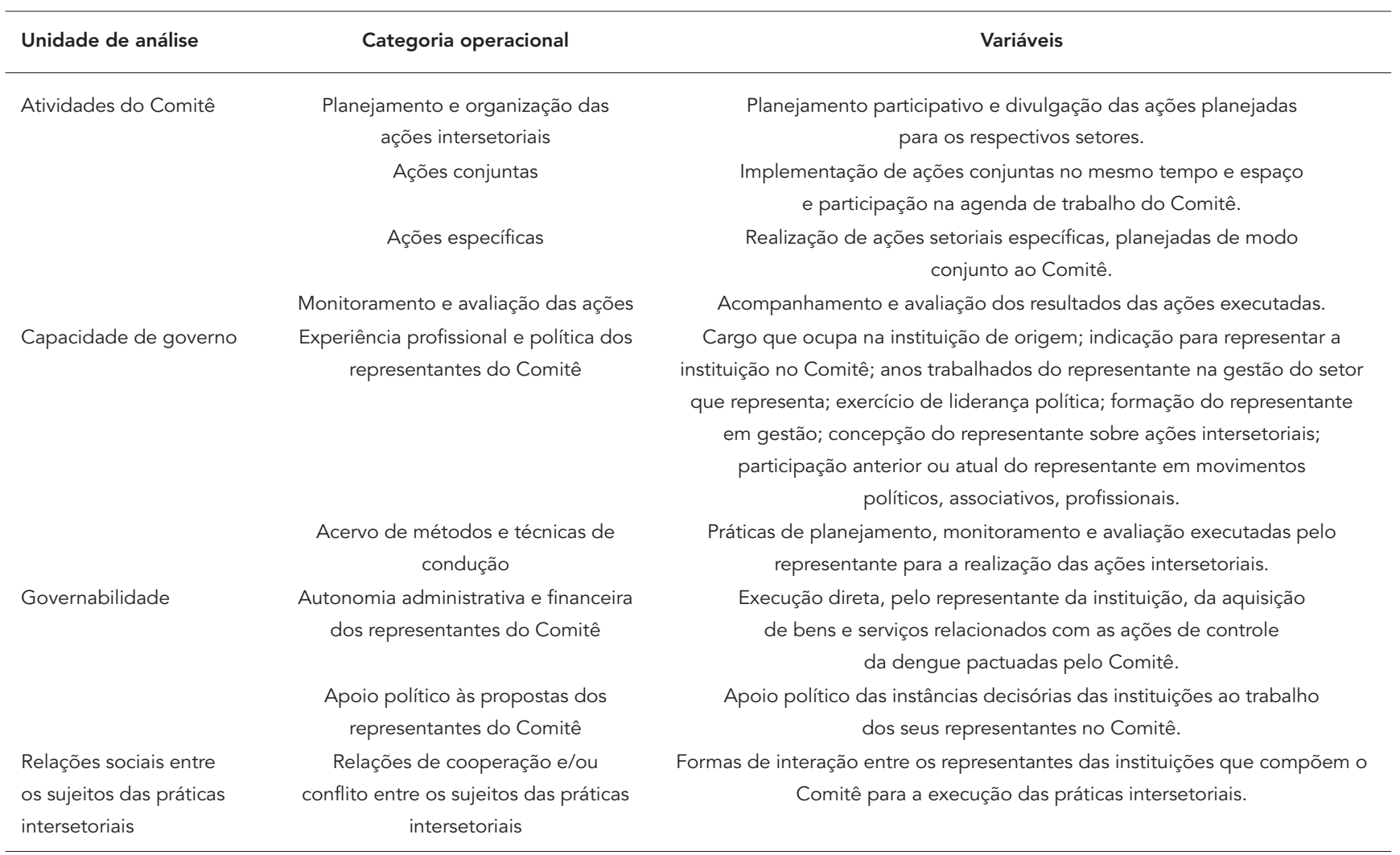

Comitê: Comitê Estadual de Mobilização Social de Prevenção e Controle da Dengue na Bahia.

com membros do Comitê, da observação direta de uma reunião de trabalho e da análise de documentos legais e planos entre maio e outubro de 2009. A pesquisa foi aprovada pelo Comitê de Ética e Pesquisa (CEP) da Universidade Estadual de Feira de Santana em 21 de maio de 2009.

Para estimar o grau de implantação das ações intersetoriais de mobilização social do Comitê, foi elaborado um modelo teórico-lógico (Figura 1). O modelo é uma representação diagramática de como uma dada intervenção deve funcionar e quais resultados são esperados 19,20; ele contém os critérios de avaliação formulados a partir das categorias analíticas do estudo. Com base nesse modelo lógico, foi desenvolvida uma matriz de medida do grau de implantação das ações intersetoriais de mobilização social para o controle da dengue na Bahia (Tabela 2).

Para cada representação institucional do Comitê entrevistada, avaliaram-se os critérios estabelecidos; foram atribuídos pontos numa escala de zero (0) a dez (10), somando-se o total dos pontos de cada representação institucional. Em seguida, foi calculado o escore final, representa- do pelo percentual da divisão da pontuação obtida pela pontuação total. Conforme esse escore final, foram considerados três graus de implantação: implantado, equivalente a $75 \%$ do escore final; parcialmente implantado, entre $50 \%$ e $75 \%$, não implantado, abaixo de $50 \%$ do escore final.

Para o processamento dos dados, realizou-se primeiro a transcrição das entrevistas e depois a leitura exaustiva dos textos. Em seguida, foi feita a classificação dos extratos das entrevistas que continham as ideias centrais dos informantes, conforme as categorias analíticas do estudo. $\mathrm{O}$ material coletado foi organizado de modo a permitir a identificação de convergências e divergências nos discursos dos entrevistados.

As evidências encontradas a partir da triangulação das técnicas de coleta de dados foram comparadas com o plano de análise. Os dados obtidos serviram para avaliar os critérios estabelecidos na matriz de medida do grau de implantação das ações intersetoriais para o controle da dengue, buscando responder à questão norteadora do estudo. 
Compontentes
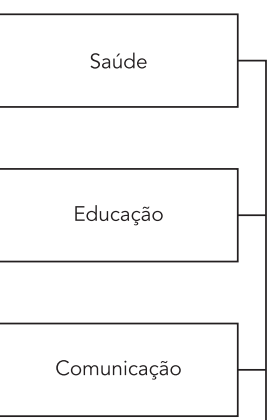

Legislação e apoio político

Saneamento e desenvolvimento

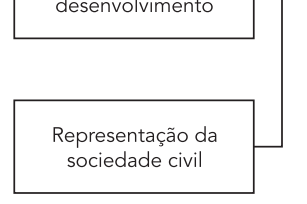

\section{Objetivo de} implantação

Processo

Atividades

Atividades
Objetivo a médio prazo

Objetivo a longo prazo

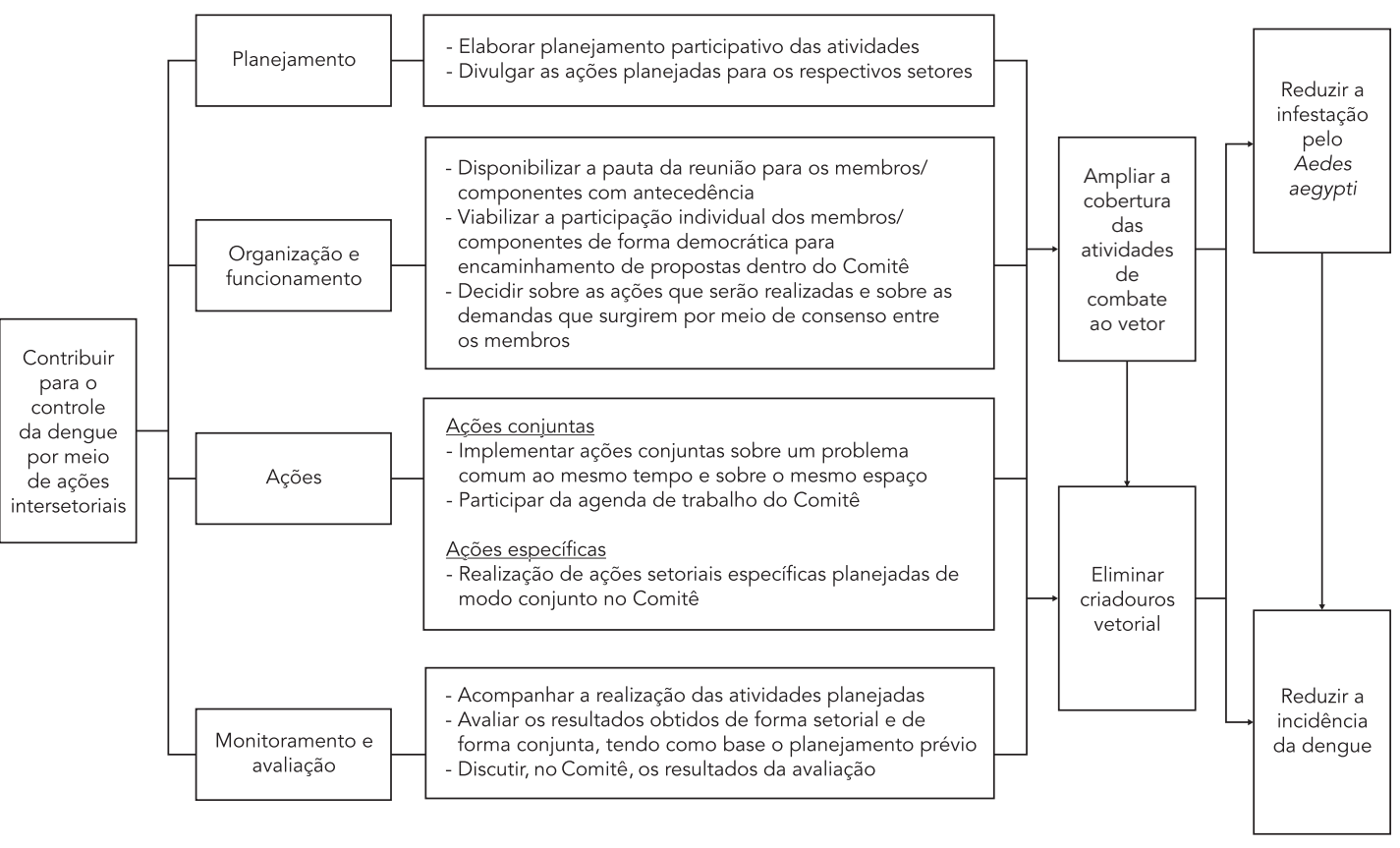

Comitê: Comitê Estadual de Mobilização Social de Prevenção e Controle da Dengue na Bahia.

\section{Resultados}

\section{Organização e funcionamento do Comitê}

A iniciativa da criação do Comitê foi uma decisão política do governador do Estado da Bahia, explicitada pela assinatura do Decreto Lei $n^{\circ}$. 11.00921 , o que indica a compreensão sobre o caráter intersetorial das ações de combate à dengue. Segundo a Minuta do Regimento Interno, a Secretaria da Saúde do Estado da Bahia (SESAB) seria responsável pela presidência e pela secretaria executiva do Comitê. As atividades seriam desenvolvidas mediante integração entre governo estadual e municípios com vistas à mobilização da população do Estado da Bahia para a realização das ações de controle da dengue.

Das treze representações entrevistadas, apenas duas desconheciam a forma de organização e a proposta de trabalho do Comitê. Uma destas representações destacou que o Comitê teria uma função consultiva, cujo propósito seria discutir pontos relevantes para o controle da dengue na
Bahia. Tal entendimento é contraditório ao que está estabelecido nos documentos analisados.

Conforme a Minuta do Regimento Interno, a periodicidade das reuniões deveria ser mensal. Um pacto entre os membros do Comitê convencionou que os encontros ocorreriam a cada dois meses, porém não foram encontradas atas das reuniões e os entrevistados reiteraram a irregularidade destas. A representação da SESAB afirmou que, mesmo não havendo periodicidade das reuniões, o Comitê estava ativo na execução do Plano Estadual de Comunicação e Mobilização Social para o Combate à Dengue.

Os membros do Comitê eram os representantes indicados pela direção das instituições que integravam essa estrutura, e, na maioria delas, o representante titular era seu dirigente máximo. Entretanto, em boa parte das reuniões do Comitê, os representantes titulares eram substituídos pelos suplentes. A indicação destes se dava ou por terem capacidade técnica ou por serem os responsáveis institucionais por ações que exigiam algum tipo de articulação com entidades da sociedade civil. 
Tabela 2

Matriz da medida do grau de implantação das ações intersetoriais de mobilização social para o controle da dengue na Bahia, Brasil.

\begin{tabular}{|c|c|c|c|}
\hline Componentes & $\begin{array}{l}\text { Representação } \\
\text { institucional }\end{array}$ & $\begin{array}{l}\text { Critérios indicativos das atribuições dos } \\
\text { representantes do comitê }\end{array}$ & $\begin{array}{l}\text { Pontuação } \\
\text { máxima }\end{array}$ \\
\hline \multirow[t]{23}{*}{ Saúde } & Secretaria da Saúde do & Agendar e convocar reuniões periódicas do Comitê. & 10 \\
\hline & Estado da Bahia & Disponibilizar a pauta da reunião para os membros/componentes com antecedência. & 5 \\
\hline & & Participar da elaboração do planejamento das atividades. & 10 \\
\hline & & Divulgar atividades planejadas para o respectivo setor. & 5 \\
\hline & & Participar na agenda de trabalho do Comitê. & 8 \\
\hline & & Realizar ações conjuntas com outros setores. & 10 \\
\hline & & Realizar ações setoriais específicas, planejadas de modo conjunto no Comitê. & 8 \\
\hline & & Acompanhar a realização das atividades planejadas. & 5 \\
\hline & & Avaliar os resultados obtidos. & 10 \\
\hline & & Governabilidade do representante da instituição. & 10 \\
\hline & & Capacidade de governo do representante da instituição. & 10 \\
\hline & & Subtotal: & 91 \\
\hline & Secretaria Municipal de & Participar regularmente das reuniões do comitê. & 8 \\
\hline & Saúde de Salvador & Participar da elaboração do planejamento das atividades. & 10 \\
\hline & & Divulgar atividades planejadas para o respectivo setor. & 5 \\
\hline & & Participar na agenda de trabalho do Comitê. & 8 \\
\hline & & Realizar ações conjuntas com outros setores. & 10 \\
\hline & & Realizar ações setoriais específicas, planejadas de modo conjunto no Comitê. & 8 \\
\hline & & Acompanhar a realização das atividades planejadas. & 5 \\
\hline & & Avaliar os resultados obtidos. & 10 \\
\hline & & Governabilidade do representante da instituição. & 10 \\
\hline & & Capacidade de governo do representante da instituição. & 10 \\
\hline & & Subtotal: & 84 \\
\hline \multirow[t]{11}{*}{ Educação } & $\begin{array}{c}\text { Secretaria da Educação } \\
\text { do Estado da Bahia }\end{array}$ & Participar regularmente das reuniões do Comitê. & 8 \\
\hline & Universidade Federal & Participar da elaboração do planejamento das atividades. & 10 \\
\hline & da Bahia & Divulgar atividades planejadas para o respectivo setor. & 5 \\
\hline & & Participar na agenda de trabalho do Comitê. & 8 \\
\hline & & Realizar ações conjuntas com outros setores. & 10 \\
\hline & & Realizar ações setoriais específicas planejadas de modo conjunto no Comitê. & 8 \\
\hline & & Acompanhar a realização das atividades planejadas. & 5 \\
\hline & & Avaliar os resultados obtidos. & 10 \\
\hline & & Governabilidade do representante da instituição. & 10 \\
\hline & & Capacidade de governo do representante da instituição. & 10 \\
\hline & & Subtotal: & 84 \\
\hline \multirow[t]{12}{*}{ Comunicação } & Secretaria de Relações & Participar regularmente das reuniões do Comitê. & 8 \\
\hline & Institucionais da Bahia & & \\
\hline & Correios & Participar da elaboração do planejamento das atividades. & 10 \\
\hline & & Divulgar atividades planejadas para o respectivo setor. & 5 \\
\hline & & Participar na agenda de trabalho do Comitê. & 8 \\
\hline & & Realizar ações conjuntas com outros setores. & 10 \\
\hline & & Realizar ações setoriais específicas planejadas de modo conjunto no Comitê. & 8 \\
\hline & & Acompanhar a realização das atividades planejadas. & 5 \\
\hline & & Avaliar os resultados obtidos. & 10 \\
\hline & & Governabilidade do representante da instituição. & 10 \\
\hline & & Capacidade de governo do representante da instituição. & 10 \\
\hline & & Subtotal: & 84 \\
\hline
\end{tabular}

(continua) 
Tabela 2 (continuação)

\begin{tabular}{|c|c|c|c|}
\hline Componentes & $\begin{array}{l}\text { Representação } \\
\text { institucional }\end{array}$ & $\begin{array}{l}\text { Critérios indicativos das atribuições dos } \\
\text { representantes do comitê }\end{array}$ & $\begin{array}{l}\text { Pontuação } \\
\text { máxima }\end{array}$ \\
\hline \multirow{11}{*}{$\begin{array}{l}\text { Legislação e } \\
\text { apoio político }\end{array}$} & Defensoria Pública do & Participar regularmente das reuniões do Comitê. & 8 \\
\hline & Estado da Bahia & Participar da elaboração do planejamento das atividades. & 10 \\
\hline & & Divulgar atividades planejadas para o respectivo setor. & 5 \\
\hline & & Participar na agenda de trabalho do Comitê. & 8 \\
\hline & & Realizar ações conjuntas com outros setores. & 10 \\
\hline & & Realizar ações setoriais específicas planejadas de modo conjunto no Comitê. & 8 \\
\hline & & Acompanhar a realização das atividades planejadas. & 5 \\
\hline & & Avaliar os resultados obtidos. & 10 \\
\hline & & Governabilidade do representante da instituição. & 10 \\
\hline & & Capacidade de governo do representante da instituição. & 10 \\
\hline & & Subtotal: & 84 \\
\hline \multirow{11}{*}{$\begin{array}{l}\text { Saneamento e } \\
\text { desenvolvimento }\end{array}$} & Empresa Baiana de & Participar regularmente das reuniões do Comitê. & 8 \\
\hline & Águas e Saneamento & Participar da elaboração do planejamento das atividades. & 10 \\
\hline & & Divulgar atividades planejadas para o respectivo setor. & 5 \\
\hline & & Participar na agenda de trabalho do Comitê. & 8 \\
\hline & & Realizar ações conjuntas com outros setores. & 10 \\
\hline & & Realizar ações setoriais específicas planejadas de modo conjunto no Comitê. & 08 \\
\hline & & Acompanhar a realização das atividades planejadas. & 5 \\
\hline & & Avaliar os resultados obtidos. & 10 \\
\hline & & Governabilidade do representante da instituição. & 10 \\
\hline & & Capacidade de governo do representante da instituição. & 10 \\
\hline & & Subtotal: & 84 \\
\hline \multirow{11}{*}{$\begin{array}{l}\text { Representação } \\
\text { da sociedade } \\
\text { civil }\end{array}$} & Diocese de Salvador & Participar regularmente das reuniões do Comitê. & 8 \\
\hline & Conselho de Entidades & Participar da elaboração do planejamento das atividades. & 10 \\
\hline & Médicas da Bahia & Divulgar atividades planejadas para o respectivo setor. & 5 \\
\hline & & Participar na agenda de trabalho do Comitê. & 8 \\
\hline & & Realizar ações conjuntas com outros setores. & 10 \\
\hline & & Realizar ações setoriais específicas planejadas de modo conjunto no Comitê. & 8 \\
\hline & & Acompanhar a realização das atividades planejadas. & 5 \\
\hline & & Avaliar os resultados obtidos. & 10 \\
\hline & & Governabilidade do representante da instituição. & 10 \\
\hline & & Capacidade de governo do representante da instituição. & 10 \\
\hline & & Subtotal: & 84 \\
\hline Total & & & 847 \\
\hline
\end{tabular}

Comitê: Comitê Estadual de Mobilização Social de Prevenção e Controle da Dengue na Bahia.

Nota: Para a Secretaria da Saúde do Estado da Bahia foram acrescentados alguns critérios diferentes, em relação aos demais setores, e aumentada a pontuação máxima para 91 pontos, tendo em vista ser esta instituição responsável pela Secretaria Executiva do Comitê.

A maioria dos entrevistados dispunha de cargos de provimento temporário que lhes permitiam tomar decisões de natureza administrativa. Esses cargos foram considerados como de gestão, pois os representantes entrevistados possuíam autonomia administrativa suficiente para tomar decisões importantes na instituição, inclusive decisões financeiras. Apenas dois deles ocupavam cargos técnicos. Das representações entrevistadas, todas tinham prática em utilizar métodos e técnicas de condução, como o planejamento, o monitoramento e a avaliação, dentro das atividades na sua instituição.
Do total de entrevistados, três estavam há menos de dois anos na instituição e três ocupavam seus cargos há mais de nove anos. A maioria tinha história atual ou pregressa de participação em movimentos associativos, tais como sociedades científicas, associações de bairro ou entidades religiosas.

Quanto à percepção dos entrevistados sobre as ações intersetoriais, apenas dois referiram-se ao conceito de intersetorialidade. Os demais relacionaram sua percepção sobre as ações intersetoriais ao grau de implantação destas, e esse conceito se restringiu a reunir diversos setores 
da sociedade em um mesmo espaço de discussão, não havendo a necessidade de realização de ações conjuntas.

\section{Ações realizadas pelo Comitê}

Entre as 13 representações entrevistadas, apenas três realizavam ações específicas para o controle da dengue de forma desarticulada ao trabalho do Comitê. Essas ações não estavam em consonância com o Plano Estadual de Comunicação e Mobilização Social para o Combate à Dengue e não eram informadas ao Comitê. As demais representações indicaram a realização dessas atividades com o conhecimento do Comitê e o apoio da SESAB. Todavia, a maior parte delas não foi planejada no espaço de discussão do Comitê, tendo sido planejada de forma individual por cada instituição.

Entre as ações conjuntas realizadas pelas instituições, citadas pelos entrevistados, destacam-se a Caminhada de Ramos, a realização de "faxinaços" e caminhadas com distribuição de material educativo. Essas ações contaram com a participação de várias instituições no dia do evento, no entanto não houve o estabelecimento de parcerias entre as instituições para a realização do planejamento de cada ação. As únicas representações que apoiavam com o fornecimento de material para a realização dos eventos eram a SESAB e a Secretaria Municipal de Saúde de Salvador (SMS-Salvador), tendo em vista a própria atribuição dessas instituições.

Neste estudo, considerou-se ainda como ação conjunta a participação nas reuniões do Comitê e nas atividades programadas por este, como o Dia D de Mobilização contra a Dengue. Todas as instituições entrevistadas participaram dessas atividades, contudo alguns representantes relataram que sua participação foi restrita em virtude de outras prioridades institucionais.

\section{Ações de mobilização dos servidores públicos}

A SESAB estabeleceu um acordo tripartite com a Fundação Luís Eduardo Magalhães (FLEM) e as Voluntárias Sociais, com o objetivo de promover a mobilização dos servidores públicos dos poderes Executivo, Legislativo e Judiciário do Estado da Bahia, em apoio à Campanha Combater o Mosquito da Dengue é Tarefa de Todos, sob a responsabilidade da SESAB.

Como metodologia para a condução da mobilização dos servidores públicos, a FLEM definiu um articulador em cada secretaria ou órgão de Estado, indicado pela própria instituição. Esse articulador deveria estimular os servidores públicos a desenvolverem ações educativas e de mobilização fora do seu local de trabalho, estendendo as ações de controle da dengue para a sociedade civil. Embora não estivesse representada como instituição componente do Comitê, a FLEM participou como responsável por algumas ações pactuadas no Plano Estadual de Comunicação e Mobilização Social para o Combate à Dengue do Comitê, incluindo atividades de mobilização para o controle da dengue em imóveis e divulgação de indicadores de avaliação do Programa Estadual de Controle da Dengue na Bahia.

Muitas das ações desenvolvidas pelas instituições representadas no Comitê estavam em consonância com o plano, porém elas aconteceram em virtude da Mobilização dos Servidores Públicos, atividade conduzida pela FLEM, visto que muitas instituições representadas no Comitê também aderiram a essa mobilização. Essa participação nas duas atividades de forma paralela gerou confusão em relação a o que seria atividade do Comitê e o que seria atividade da Mobilização dos Servidores Públicos, visto que muitas das ações planejadas pelo grupo de trabalho da FLEM também estavam pactuadas no Plano.

O trabalho conduzido pela FLEM foi compreendido pelos entrevistados como sendo uma extensão das ações do Comitê. De acordo com o que foi relatado e com a observação sistemática, o trabalho do Comitê praticamente se restringiu às ações de mobilização dos servidores públicos.

O sucesso das ações realizadas pela FLEM fez emergir a possibilidade de essa instituição se tornar a Secretaria Executiva do Comitê, o que se oficializou com um plano de ação elaborado pela Fundação, com base no Plano Estadual de Comunicação e Mobilização Social para o Combate à Dengue. No entanto, a formalização da FLEM como secretaria executiva não ocorreu por causa de impedimentos administrativos na contratação da instituição.

\section{Métodos e técnicas de condução: planejamento, monitoramento e avaliação}

Foi construído, no processo de trabalho do Comitê, o Plano Estadual de Comunicação e Mobilização Social para o Combate à Dengue, elaborado a partir das diretrizes nacionais e estaduais do Programa de Controle da Dengue.

A construção do Plano se deu de forma coletiva durante o processo das reuniões. Inicialmente, foi realizado um levantamento sobre como cada instituição poderia contribuir para as ações de controle da dengue que seriam desenvolvidas. Em seguida, foi organizado um grupo menor para estruturar o formato final do Plano, o qual, após discussões e elaborações neste grupo, foi 
apresentado no espaço de discussão do Comitê para aprovação.

O Plano incluiu ações que objetivavam não só sensibilizar a sociedade civil para as medidas de prevenção da dengue e os gestores para a importância de se ampliarem as ações de controle da doença, como também incentivar a participação da população na fiscalização dessas ações. Mesmo não existindo atas das reuniões do Comitê, os membros deste acordaram em reunião que se responsabilizariam por fazer a divulgação do Plano em suas instituições. Das representações entrevistadas, essa ação não aconteceu em quatro instituições.

O acompanhamento e a avaliação das ações especificadas no Plano não foram realizados pelo Comitê, apesar da indicação da existência de instrumentos e metodologia de avaliação das ações. A exceção diz respeito às ações de Mobilização dos Servidores Públicos, atividade que foi conduzida pela FLEM.

Destaque-se que, mesmo não existindo por parte do Comitê uma avaliação sistemática das ações realizadas pelas instituições, a grande maioria das representações entrevistadas afirmou realizar avaliações das suas ações específicas, sendo essa uma rotina da própria instituição. Por sua vez, a SESAB realiza anualmente a avaliação do Programa Estadual de Controle da Dengue, atividade que envolve a avaliação de todos os componentes do programa.

A ausência de ações sistemáticas de monitoramento e avaliação por parte do Comitê foi justificada pela epidemia de dengue ocorrida na Bahia no ano de 2009. Os técnicos responsáveis pela organização das ações do Comitê eram os mesmos responsáveis por tentar controlar a epidemia no Estado.

Grau de implantação das ações intersetoriais de mobilização social para o controle da dengue na Bahia

O escore final do grau de implantação das ações intersetoriais de mobilização social para o controle da dengue na Bahia foi de $55,72 \%$, com classificação final de parcialmente implantado.

A análise do grau de implantação por representação entrevistada (Tabela 3) evidenciou grande variação do nível de envolvimento das instituições nas ações propostas pelo Comitê. A maioria das representações havia implantado parcialmente as ações intersetoriais de educação em saúde, comunicação e mobilização social, com exceção de três instituições, cujas ações intersetoriais não foram implantadas. A instituição que apresentou melhor desempenho na implantação das ações intersetoriais foi a SESAB.

\section{Fatores facilitadores e restritivos para} a implantação de ações intersetoriais

Os entrevistados apontaram como fatores facilitadores para a estruturação do Comitê o interesse e o compromisso do governador para com essa proposta, o que estimulou o envolvimento das várias instituições representadas com as atividades pactuadas.

Outro ponto positivo identificado foi que a maioria dos entrevistados assumia cargos de gestão e eram responsáveis diretos pela aquisição de bens e serviços relacionados às ações de controle da dengue pactuadas pelo Comitê. No entanto, a autonomia dos representantes das instituições era restrita quanto à gerência de recursos financeiros. A autorização para a realização de despesas dependia da negociação entre o servidor que representava a instituição no Comitê e o seu dirigente máximo. Ressalte-se que tal negociação não se constituiu em uma dificuldade na maioria das instituições, desde que tal solicitação ocorresse com antecedência.

À exceção da Secretaria de Educação, os representantes do Comitê dispunham de apoio político dos dirigentes das instituições, o que evidencia certo acúmulo de capital político, que facilitou a operacionalização das propostas de trabalho.

A grande maioria das representações entrevistadas apontou como dificuldades na estruturação das atividades do Comitê a falta de uma secretaria executiva para conduzir e coordenar as ações planejadas, equipe insuficiente e a falta de estrutura (material e condições de trabalho). As ações da Secretaria Executiva do Comitê estavam sendo realizadas por técnicos da SESAB, os quais tinham outras responsabilidades dentro da estrutura funcional desta Secretaria. Esse acúmulo de atribuições sobre os técnicos responsáveis pela Secretaria Executiva resultou em priorizar outras atividades da Secretaria da Saúde em prol das ações do Comitê.

Essa insatisfação em relação às muitas atribuições dos técnicos da SESAB, que dificultou a operacionalização do trabalho da Secretaria Executiva, é contraditório ao que foi estabelecido na Minuta do Regimento Interno, elaborada pelo próprio Comitê. Nesse documento, determinouse que tanto a presidência do Comitê quanto a Secretaria Executiva do mesmo deveriam ser desempenhadas por representantes da SESAB.

A maior parte dos candidatos destacou existir o sentimento de cooperação, negando qualquer tipo de disputa de poder. Apesar dessa afirmativa, ficou evidente a existência de conflitos no desenvolvimento das atividades, e os mesmos representantes que afirmaram existir cooperação 
Distribuição do grau de implantação das ações intersetoriais de mobilização social para o controle da dengue na Bahia, Brasil, conforme as representações do Comitê.

\begin{tabular}{|c|c|c|c|c|}
\hline Instituição & $\begin{array}{l}\text { Pontuação } \\
\text { máxima }\end{array}$ & $\begin{array}{l}\text { Pontuação } \\
\text { obtida }\end{array}$ & $\begin{array}{c}\text { Grau de } \\
\text { implantação (\%) }\end{array}$ & Classificação \\
\hline Secretaria da Saúde do Estado da Bahia & 91 & 68 & 74,72 & Parcialmente implantado \\
\hline Secretaria Municipal de Saúde de Salvador & 84 & 42 & 50,00 & Parcialmente implantado \\
\hline Secretaria da Educação do Estado da Bahia & 84 & 56,5 & 67,26 & Parcialmente implantado \\
\hline Universidade Federal da Bahia & 84 & 34 & 40,47 & Não implantado \\
\hline Secretaria de Relações Institucionais da Bahia & 84 & 24,5 & 29,16 & Não implantado \\
\hline Correios & 84 & 58,5 & 69,24 & Parcialmente implantado \\
\hline Defensoria Pública & 84 & 52,5 & 62,50 & Parcialmente implantado \\
\hline Empresa Baiana de Águas e Saneamento & 84 & 60,5 & 72,02 & Parcialmente implantado \\
\hline Diocese de Salvador & 84 & 55,5 & 66,07 & Parcialmente implantado \\
\hline Conselho de Entidades Médicas da Bahia & 84 & 20 & 23,80 & Não Implantado \\
\hline
\end{tabular}

evidenciaram, também, relações de conflitos. A disputa de poder só foi assumida de forma aberta na relação estabelecida entre a gestão estadual, que está à frente da organização do Comitê, e a gestão do Município de Salvador, local onde ocorreu a maioria das ações do Comitê. Isso ficou evidente por causa das diferenças político-partidárias existentes entre as duas gestões.

\section{Discussão}

As ações intersetoriais no processo de trabalho do Comitê não estão suficientemente implantadas e operacionalizadas. Destaque-se que a implantação das ações intersetoriais ocorreu de forma distinta em cada instituição representada no Comitê, demonstrando que à medida que se aumenta o número de partes envolvidas e de interesses, aumenta a dificuldade de se implementarem as ações intersetoriais 12 .

As instituições que tiveram melhor desempenho na implantação das ações intersetoriais para o controle da dengue foram aquelas que também participaram da Mobilização dos Servidores Públicos, atividade conduzida pela FLEM. Isso demonstra a importância de uma equipe condutora para a implementação de práticas intersetoriais.

Na organização do trabalho do Comitê, havia uma equipe condutora, definida como Secretaria Executiva, cujas ações eram desempenhadas pela instituição SESAB, que ainda tinha como atribuição presidir as reuniões do Comitê. Essa centralização de funções sobre uma mesma instituição demonstrou a concentração de poder e de decisões sobre um único setor, o que vai de encontro com a proposta da intersetorialidade, caracterizada como espaço de compartilhamento de saber e poder 8,16 .

A responsabilização do setor saúde pela condução das ações no Comitê indica a manutenção de um olhar fragmentado sobre o objeto, no caso a dengue. Essa doença é facilmente identificada como objeto do setor saúde, no entanto outros setores podem ter dificuldade de reconhecê-la como um objeto pertencente à sua área de atuação. A dificuldade dos profissionais de olharem para além do seu objeto específico 16 demonstra a necessidade de mudanças na formação profissional, mudanças de valores e de cultura, para se conseguir pôr em prática a proposta da intersetorialidade 8,11 .

Do mesmo modo, o sucesso das ações de mobilização social irá depender dos sentidos, significados, valores e crenças que a sociedade atribui ao problema. Torna-se necessário que a mensagem de mobilização social, neste caso o controle da dengue, ganhe significado e relevância no seio da sociedade e desencadeie um processo de mobilização em face do problema 13 .

Além das ações de educação em saúde, comunicação e mobilização social, a SESAB é também responsável por muitas outras atividades relacionadas ao controle da dengue, incluindo assistência aos pacientes, vigilância epidemiológica, combate ao vetor, entre outras. Esse acúmulo de atribuições, juntamente com a epidemia de dengue enfrentada pelo Estado da Bahia no ano de 2009, resultou no não cumprimento das funções da Secretaria Executiva do Comitê, o que gerou um impacto negativo na implantação das ações intersetoriais. 
Outro fator que pode ter sido restritivo às ações intersetoriais e que, de certo modo, tornou os resultados previsíveis foi a limitada compreensão conceitual sobre a intersetorialidade. Tal resultado também foi encontrado em outros estudos 5,22 .

Ao comparar as ações realizadas pelas instituições pertencentes ao Comitê com o que foi planejado, há indícios da não utilização do planejamento como instrumento de trabalho; tampouco houve o monitoramento e a avaliação desse plano de trabalho pelo Comitê. Portanto, as técnicas de condução utilizadas se restringiram apenas à primeira etapa de construção do planejamento, um processo burocrático e normativo. A intersetorialidade não pode se limitar apenas à produção de um planejamento; deve haver continuidade do trabalho por meio do acompanhamento e da avaliação 11 .

Outros estudos sobre intersetorialidade apontaram para não utilização do planejamento, para as diferenças existentes entre o plano de trabalho das instituições e o planejamento inicial e para as diferenças entre os resultados obtidos e os objetivos iniciais $5,23,24$.

Sobre as ações desenvolvidas pelas instituições representadas no Comitê, observou-se que a grande maioria utilizou sua estrutura de trabalho e realizou ações de mobilização social que contribuíssem para o controle da dengue. Entretanto, a maior parte dessas ações se restringiu a ações setoriais específicas, não sendo estabelecidas alianças estratégicas com outros setores para o planejamento e a execução dessas atividades. Dessa forma, verifica-se que o Comitê conseguiu transformar o tema dengue em um tema transversal dentro do processo de trabalho das instituições, porém o trabalho desenvolvido continuou fragmentado e sem articulação, indicando a fragilidade no processo de intersetorialidade desencadeado pelo Comitê.

Dentre as ações desenvolvidas que implicaram a participação de vários setores estabelecendo parcerias, constatou-se que existiu maior articulação entre os segmentos governamentais, havendo pouca articulação com a sociedade civil organizada. Resultado semelhante foi evidenciado em outros estudos 25,26.

A motivação inicial e disponibilidade das instituições participantes do Comitê foram estimuladas pela prioridade dada pelo governo do Estado às ações de controle da dengue. A intersetorialidade é mais bem experimentada quando há apoio político dos gestores e política pública específica de atuação governamental 26,27.

Quanto à governabilidade dos sujeitos das práticas intersetoriais, chamou atenção a autonomia dos representantes do Comitê nas suas instituições de origem. Nas situações em que a autonomia desses sujeitos era limitada, principalmente em relação a recursos financeiros, observou-se que eles possuíam capital político 14 suficiente para conseguir ajustar a proposta de trabalho relativa ao controle da dengue à dinâmica de trabalho da sua instituição.

Representantes com governabilidade dentro das suas instituições favoreceram a operacionalização das ações propostas no espaço de discussão do Comitê. Isso foi evidenciado pela medida do grau de implantação, segundo a qual as instituições que tiveram pior desempenho na implantação das ações intersetoriais foram aquelas cujos representantes eram sujeitos com governabilidade limitada. Resultado semelhante foi encontrado por Burlandy 28 ao estudar a intersetorialidade no campo da segurança alimentar e nutricional. A autora identificou como fator facilitador das práticas intersetoriais a formação de grupos gestores interministeriais com grande governabilidade. Ferreira \& Vieira-da-Silva 23 encontraram como obstáculo para a implantação das práticas intersetoriais a baixa governabilidade e o pouco poder de decisão dos sujeitos responsáveis pelas ações intersetoriais.

No processo de trabalho do Comitê foram identificadas algumas tensões entre seus membros. Os conflitos que mais emergiram relacionavam-se à responsabilização das instituições pelos problemas relacionados à manutenção de focos do mosquito em espaços públicos, má qualidade da assistência e descontinuidade das supervisões em áreas de risco para focos do mosquito. Essas tensões se manifestaram na relação estabelecida entre o estado e o município, na qual a disputa de poder ficou evidente.

Este estudo aponta para importância do apoio político das entidades governamentais como fator favorecedor da articulação intersetorial. No entanto, esse apoio, por si só, não se constitui condição sine qua non da sua implantação, como pôde ser observado.

Com os resultados do presente estudo, acredita-se que, para o avanço das práticas intersetoriais, faz-se necessário não só compromisso coletivo e governamental, mas também equipe condutora responsável pelo trabalho, a qual tenha capacidade técnica e política, além de tempo disponível para conduzir, acompanhar e avaliar as atividades realizadas. A equipe deve ser capaz ainda de estimular a articulação entre os diferentes setores, dissipando as barreiras disciplinares ainda rígidas. É igualmente importante promover encontros com os representantes dos vários setores de forma mais constante, divulgar os resultados do trabalho realizado e fazer avaliações periódicas. Essas ações poderiam contribuir para 
manter os setores mais motivados e comprometidos com a articulação intersetorial.

Por fim, observou-se que a constituição do Comitê e sua proposta de trabalho serviram de estimulo à articulação intersetorial, porém a intersetorialidade ficou restrita ao plano retórico. A implantação das ações intersetoriais, na prática, permanece um desafio a ser conquistado.

\section{Resumo}

As discussões sobre o processo saúde-doença e promoção da saúde indicam a necessidade de extrapolar os limites do setor saúde e articular os conhecimentos de vários setores para promover melhor condição de saúde para a população. Diante disso, a intersetorialidade surgiu como uma nova lógica norteadora das políticas públicas. O objetivo geral foi analisar o processo de implantação das ações intersetoriais de mobilização social para o controle da dengue na Bahia, no período de 2008-2009. Trata-se de pesquisa avaliativa. Foi elaborado um modelo lógico norteador da construção de critérios utilizados para estimar o grau de implantação dessas ações (implantado - parcialmente implantado - não implantado). Os resultados apontaram como principal fator facilitador das práticas intersetoriais o apoio político das entidades governamentais $e$, como entraves, a concentração de atribuições sobre um único setor e a não utilização do planejamento como instrumento de trabalho. Os resultados do estudo evidenciam que a articulação intersetorial permanece um desafio a ser conquistado.

Ação Intersetorial; Dengue; Participação Social; Políticas Públicas; Avaliação

\section{Colaboradores}

E. C. Lima redigiu e participou de todas as etapas de produção do artigo. A. L. Q. Vilasbôas contribuiu na elaboração do desenho do artigo, definição da metodologia e revisão dos resultados.

\section{Referências}

1. Brasil. Constituição Federal. Brasília: Senado Federal; 1988.

2. Brasil. Lei no ${ }^{\circ} 8.080$, de 19 de setembro de 1990 . Diário Oficial da União 1990; 20 set.

3. Rivera FRU, Artmann E. Promoção da saúde e planejamento estratégico situacional: intersetorialidade na busca de maior governabilidade. In: Czeresnia D, Freitas CM, organizadores. Promoção da saúde: conceitos, reflexões, tendências. Rio de Janeiro: Editora Fiocruz; 2009. p. 183-206.

4. Junqueira LAP, Inojosa RM, Komatsu S. Descentralização e intersetorialidade na gestão pública municipal no Brasil: a experiência de Fortaleza. In: XI Concurso de Ensayos del CLAD. El tránsito de la cultura burocrática al modelo de la gerencia pública: perspectivas, posibilidades y limitaciones. Caracas; 1997. http://unpan1.un.org/intradoc/ groups/public/documents/clad/unpan003743. pdf (acessado em 20/Out/2007).

5. Ckagnazaroff IB, Melo JSC, Carvalho, DN. Da gestão da intersetorialidade: o caso do programa $\mathrm{BH}$ Cidadania, Brasil. In: X Congresso Internacional do CLAD sobre a Reforma do Estado e da Administração Pública. Chile; 2005. http://wwww.iij.de recho.ucr.ac.cr/archivos/documentacion/inv\%20 otras\%20entidades/CLAD/CLAD\%20X/documen tos/ckagnaza.pdf (acessado em 02/Fev/2011)

6. Buss PM. Uma introdução ao conceito de promoção da saúde. In: Czeresnia D, Freitas CM. Promoção da saúde: conceitos, reflexões, tendências. Rio de Janeiro: Editora Fiocruz; 2009. p. 19-42. 
7. Westphal MF, Mendes R. Cidade saudável: uma experiência de interdisciplinaridade e intersetorialidade. Rev Adm Pública 2000; 6:47-61.

8. Comerlatto D, Matielli A, Colliselli L, Renk EC, Kleba ME. Gestão de políticas públicas e intersetorialidade: diálogo e construções essenciais para os conselhos municipais. Revista Katálysis 2007; 10:265-71.

9. Secretaria da Saúde do Estado da Bahia. Minuta do Regimento do Comitê Estadual de Mobilização Social de Prevenção e Controle da Dengue. Salvador: Secretaria da Saúde do Estado da Bahia; 2008.

10. Fundação Nacional de Saúde, Ministério da Saúde. Programa Nacional de Controle da Dengue. Brasília: Ministério da Saúde; 2002.

11. Junqueira LA. A gestão intersetorial das políticas sociais e o terceiro setor. Saúde Soc 2004; 13:25-36.

12. Zunzunegui MV, Béland F. Políticas intersectoriales para abordar el reto del envejecimiento activo. Gac Sanit 2010; 24 Suppl 1:68-73.

13. Rangel ML. Dengue: educação, comunicação e mobilização na perspectiva do controle - propostas inovadoras. Interface Comun Saúde Educ 2008; 12:433-41.

14. Matus C. Política, planejamento \& governo. Brasília: Instituto de Pesquisa Econômica Aplicada; 1993.

15. Campos RO. O planejamento no labirinto: uma viagem hermenêutica. São Paulo: Editora Hucitec; 2003.

16. Moysés SJ, Moysés ST, Krempel MC. Avaliando o processo de construção de políticas públicas de promoção de saúde: a experiência de Curitiba. Ciênc Saúde Coletiva 2004; 9:627-41.

17. Testa M. Pensamento estratégico e lógica de programação: o caso da saúde. São Paulo: Editora Hucitec; 1995.

18. Denis JL, Champagne F. Análise de implantação. In: Hartz ZMA, Vieira-da-Silva LM, organizadores. Avaliação em saúde: dos modelos teóricos à prática na avaliação de programas e sistemas de saúde. Salvador: Edufba/Rio de Janeiro: Editora Fiocruz; 2005. p. 49-88.

19. Frias PGF, Lira PIC, Hartz ZMA. Avaliação da implantação de um projeto para redução da mortalidade infantil. In: Hartz ZMA, Vieira-da-Silva LM, organizadores. Avaliação em saúde: dos modelos teóricos à prática na avaliação de programas e sistemas de saúde. Salvador: Edufba/Rio de Janeiro: Editora Fiocruz; 2005. p. 151-206.
20. Medina MG, Silva GAP, Aquino R, Hartz ZMA. Uso de modelos teóricos na Avaliação em Saúde: aspectos conceituais e operacionais. In: Hartz ZMA, Vieira-da-Silva LM, organizadores. Avaliação em saúde: dos modelos teóricos à prática na avaliação de programas e sistemas de saúde. Salvador: Edufba/Rio de Janeiro: Editora Fiocruz; 2005. p. 41-63.

21. Bahia. Decreto Lei no ${ }^{\circ} .11 .009$, de 18 de Abril de 2008. Cria o Comitê Estadual de Mobilização Social de Prevenção e Controle da Dengue, no âmbito do Estado da Bahia, e dá outras providências. Diário Oficial da União 2008; 18 abr.

22. Paula KA, Palha PF, Protti ST. Intersetorialidade: uma vivência prática ou um desafio a ser conquistado? Interface Comun Saúde Educ 2004; 8: 331-48.

23. Ferreira VSCF, Vieria-da-Silva LM. Intersetorialidade em saúde: um estudo de caso. In: Hartz ZMA, Vieira-da-Silva LM, organizadores. Avaliação em saúde: dos modelos teóricos à prática na avaliação de programas e sistemas de saúde. Salvador: Edufba/Rio de Janeiro: Editora Fiocruz; 2005. p. 103-50.

24. Magalhães R, Bodstein R. Avaliação de iniciativas e programas intersetoriais em saúde: desafios e aprendizados. Ciênc Saúde Coletiva 2009; 14:861-8.

25. Fernandes DM. Análise da articulação intersetorial de um programa social em nível local - experiência do município de Petrópolis/RJ [Dissertação de Mestrado]. Rio de Janeiro: Escola Nacional de Saúde Pública Sergio Arouca, Fundação Oswaldo Cruz; 2005.

26. Mannheimer LN, Gulis G, Östlin P. Introducing health impact assessment: an analysis of political and administrative intersectoral working methods. Eur J Public Health 2007; 17:526-31.

27. Giovanella L, Mendonça MHM, Almeida PF, Escorel S, Senna MCM, Fausto MCR, et al. Saúde da família: limites e possibilidades para uma abordagem integral de atenção primária à saúde no Brasil. Ciênc Saúde Coletiva 2009; 14:783-94.

28. Burlandy LA. Construção da política de segurança alimentar e nutricional no Brasil: estratégias e desafios para a promoção da intersetorialidade no âmbito federal de governo. Ciênc Saúde Coletiva 2009; 14:851-60.

Recebido em 08/Set/2010

Versão final reapresentada em 09/Mai/2011

Aprovado em 19/Mai/2011 